J. Dairy Sci. 98:7131-7141

http://dx.doi.org/10.3168/jds.2014-9144

(C) American Dairy Science Association ${ }^{\circledR}, 2015$.

\title{
Rumen fermentation, blood metabolites, and growth performance of calves during transition from liquid to solid feed: Effects of dietary level and particle size of alfalfa hay
}

\author{
M. Nemati, ${ }^{*}$ H. Amanlou, ${ }^{*}$ M. Khorvash,† B. Moshiri,‡ M. Mirzaei,§ M. A. Khan,\# and M. H. Ghaffari† ${ }^{1}$ \\ *Department of Animal Science, Faculty of Agricultural Sciences, University of Zanjan, Zanjan 313-45195, Iran \\ †Department of Animal Science, College of Agriculture, Isfahan University of Technology, Isfahan 84156-83111, Iran \\ ¥Ghiam Dairy Complex, Isfahan 833111-4761, Iran \\ §Department of Animal Science, Faculty of Agriculture and Natural Resources, Arak University, 38156-8-8349 Arak, Iran \\ \#Animal Nutrition and Health Group, Grasslands Research Centre, AgResearch Limited Palmerston North 4442, New Zealand
}

\begin{abstract}
This study evaluated the effects of particle size (PS) and dietary level of alfalfa hay $(\mathrm{AH})$ on rumen fermentation parameters, blood metabolites, eating behavior, and growth performance in dairy calves during transition from liquid to solid feed. Sixty newborn dairy calves $(41 \pm 2.5, \mathrm{~kg}$ of body weight) were used in a 2 $\times 2$ factorial arrangement with the factors dietary $\mathrm{AH}$ level (medium, $12.5 \%$, or high, $25 \%$, on DM basis) and PS (fine $=1 \mathrm{~mm}$ or medium $=3 \mathrm{~mm}$, as geometric means) of AH. Hence, the dietary treatments were (1) medium level of AH with fine PS (M-FPS), (2) medium level of AH with medium PS (M-MPS), (3) high level of AH with fine PS (H-FPS), and (4) high level of AH with medium PS (H-MPS). Particle size of AH did not affect total DMI (TDMI) during the preweaning period, although TDMI was greater for calves fed MPS than in those fed FPS during the postweaning and overall periods. Calves fed MPS spent more time eating solid feed and ruminating and less time on nonnutritive oral behaviors compared with FPS calves. The dietary level of AH did not affect behavioral parameters. Average daily gain of calves was not affected by dietary treatment before weaning. During the postweaning and overall periods, average daily gain was greater in calves fed MPS than in those fed FPS at the $25 \% \mathrm{AH}$ level, but this effect was absent with $12.5 \%$ AH. Furthermore, the rumen $\mathrm{pH}$ values on $\mathrm{d} 35$ and 70 of the study were greater for MPS than for FPS, regardless of the dietary level of AH. Effects of AH level, PS, and their interaction did not affect blood glucose concentrations in developing calves. These results indicate that feed intake, feeding behavior, rumen fermentation parameters, and blood $\beta$-hydroxybutyrate concentration may be affected by
\end{abstract}

Received November 23, 2014.

Accepted April 21, 2015.

${ }^{1}$ Corresponding author: morteza.h.g@gmail.com rations differing in forage PS; thus, providing calves with MPS can improve calf performance and reduce their nonnutritive oral behaviors.

Key words: alfalfa hay, particle size, dairy calf

\section{INTRODUCTION}

Physical and metabolic development of the reticulorumen in young calves is the prerequisite to their transition from a preruminant milk diet to a solid diet based on grain forage (Drackley, 2008). Although rumen development in young calves is affected by many factors (Baldwin et al., 2004), it is mainly dictated by the amount and nature of the solid feed offered (Khan et al., 2011). Development of the rumen epithelium is triggered by the VFA produced during microbial fermentation of ingested solid feed in the rumen (Baldwin et al., 2004). Development of rumen musculature, rumen movements, and the capacity of the rumen are influenced by the physical stimuli provided by the bulk of the ingested material (Beharka et al., 1998).

Cereal-based starter diets generally contain higher levels of fermentable carbohydrates than forages, which provide greater amounts of VFA to stimulate rumen papillae when they ferment in the rumen (Lesmeister and Heinrichs, 2004; Khan et al., 2008). Ingestion of forage provides bulk in the rumen and thereby promotes rumen musculature and helps maintain the integrity of the rumen epithelium in developing calves (Beharka et al., 1998; Beiranvand et al., 2014b). Forage provision to young calves is generally discouraged because forage is less energy intensive and digestible compared with starter diets, and could, therefore, delay rumen epithelial development and suppress growth in young ruminants (Stobo et al., 1966; Hill et al., 2008, 2009). Furthermore, the guidelines of National Research Council (NRC, 2001) do not include any recommendations for fiber provision for developing calves. However, recent studies have demonstrated beneficial effects of 
feeding forage (grasses and legumes) early in life on rumen fermentation (Castells et al., 2013; Terré et al., 2013), rumen $\mathrm{pH}$ (Laarman and Oba, 2011), rumen development, feed consumption, and growth performance (Khan et al., 2011; Castells et al., 2012; Montoro et al., 2013; Beiranvand et al., 2014b). Furthermore, Castells et al. (2013) reported increased expression of a VFA transporter (mono-carboxylate transporter 1) in the rumen epithelium of calves that had access to forage compared with calves fed pelleted starter without forage. Previous studies (Castells et al., 2013; Beiranvand et al., 2014a,b) have shown enhanced concentrate intake and growth performance in young calves supplemented with forage. Particle size (PS) of the dietary forage affects the rumen environment, with high amounts of long and coarse forage resulting in decreased intake because of gut fill in dairy cows (Mirzaei et al., 2015). This may also apply to dairy calves, especially because of the limited capacity of their reticulorumen (Beharka et al., 1998; Godden et al., 2009).

We hypothesized that PS of alfalfa hay $(\mathbf{A H})$ in the diet with rapidly degradable starch, as in barley grain, may have the potential to modify rumen conditions and to improve the performance of dairy calves. Hence, 2 levels of PS (fine and medium) were combined with 2 levels of $\mathrm{AH}$ (12.5 and $25 \%$ of dietary DM) in foragesupplemented diets to investigate their interaction on feed intake, rumen fermentation parameters, feeding behavior, and growth performance in dairy calves.

\section{MATERIALS AND METHODS}

The experiment was conducted on a local dairy farm (Ghiam Esfahan Plantation and Domesticated Co., Isfahan, Iran). All the calves were cared and managed according to the guidelines of Iranian Council of Animal Care (1995).

\section{Calves, Management, and Treatments}

Sixty 3 -d-old Holstein male dairy calves $(41 \pm 2.5 \mathrm{~kg}$ of BW) were separated from their dams, weighed, and moved to individual pens $(1.2 \times 2.5 \mathrm{~m})$ bedded with sawdust that was renewed every $48 \mathrm{~h}$. The animals were fed 3 to $4 \mathrm{~L}$ of colostrum within 2 to $6 \mathrm{~h}$ after birth. Colostrum feeding continued for the first $2 \mathrm{~d}$ of life. Calves were fed whole milk $(4 \mathrm{~L} / \mathrm{d})$, at a rate of $10 \%$ of BW, containing $3.22 \pm 0.11 \%$ fat, $2.96 \pm 0.07 \% \mathrm{CP}$, $4.92 \pm 0.05 \%$ lactose, and $11.77 \pm 0.15 \%$ TS in steel buckets twice daily at 0900 and $1700 \mathrm{~h}$ from d 3 to 47 , followed by morning feeding $(2 \mathrm{~L} / \mathrm{d})$ from 47 to $50 \mathrm{~d}$ of age before being weaned on $\mathrm{d} 51$ of age.

The calves were randomly assigned $(\mathrm{n}=15$ per treatment) in a $2 \times 2$ factorial arrangement to a medium
(12.5\% on DM basis) and a high dietary level of $\mathrm{AH}$ ( $25 \%$ on DM basis) with a fine (1 mm; geometric mean) or medium PS (3 mm; geometric means). Calves were assigned to 1 of 4 treatments: (1) medium level of $\mathrm{AH}$ with fine PS (M-FPS), (2) medium level of AH with medium PS (M-MPS), (3) high level of AH with fine PS (H-FPS), and (4) high level of AH with medium PS (H-MPS). The ingredient and chemical composition of the experimental diets are shown in Table 1. All the diets were formulated and to be isoenergetic and isonitrogenous according to the Cornell Net Carbohydrate and Protein System version 5.1 (Fox et al., 2000 ). For the first $16 \mathrm{~d}$, all calves received the starter diet without forage provision. From d 16 onward, AH was mixed with finely ground concentrates and provided as a TMR. Starter containing AH (TMR) was fed ad libitum to permit at least $10 \%$ orts (i.e., the portion of the starter not consumed over a 24-h period), and TMR feed refusal from each individual calf was collected at $0800 \mathrm{~h}$. Calves had ad libitum access to water and starter throughout the study. Before the experiment, AH was chopped (Golchin Trasher Hay Co., Isfahan, Iran) to obtain fine (1 $\mathrm{mm}$, geometric mean) and medium (3 mm, geometric mean) PS. At least 6 representative samples were collected from each PS and used for analyzing PS distribution of AH by the Penn State Particle Separator (PSPS; Table 2). Geometric mean PS was calculated as described by the American Society of Agricultural Engineers (ASAE, 1996; method S424.1).

\section{Sampling}

Intakes of calf starter (forage and starter feed, as TMR) and total DMI (milk, starter feed, and forage) were measured daily and BW were recorded weekly during the preweaning (wk 1 to 7 ), postweaning (wk 8 to 10), and overall periods (wk 1 to 10). Amounts of feed offered and refused were recorded daily for each individual calf. Preweaning, postweaning, and overall means of total DMI (milk solids, starter feed), ADG, and feed efficiency ( $\mathrm{kg}$ of BW gain $/ \mathrm{kg}$ of total DMI) were also calculated.

Body measurements at weaning (d 51) and at the end of the study (d 71), including body length (distance between the points of shoulder and rump), body girth (the measurement of the distance around the belly over the part of the back before morning feeding), withers height (distance from base of the front feet to the withers), heart girth (circumference of the chest), hip height (distance from base of the rear feet to hook bones), and hip width (distance between the points of hook bones), of the calves were performed according to the method described by Khan et al. (2007). 
Table 1. Ingredients and chemical compositions of experimental diets with different (12.5 and $25 \%$ ) levels of alfalfa hay $(\mathrm{AH})$

\begin{tabular}{lcc}
\hline & \multicolumn{2}{c}{ Concentration in the diet $^{1}$} \\
\cline { 2 - 3 } Item & $12.5 \% \mathrm{AH}$ & $25 \% \mathrm{AH}$ \\
\hline Ingredient (\% of DM) & & \\
Alfalfa hay & 12.5 & 25.0 \\
Barley grain & 57.5 & 45.0 \\
Soybean meal (45\% CP) & 25 & 20.8 \\
Extruded soybean & 1.6 & 5.0 \\
Calcium carbonate & 1.0 & 1.0 \\
Energy booster 100 & 0.4 & 1.2 \\
Vitamin and mineral premix & 3 & 1.5 \\
Salt & 1.5 & 0.5 \\
Chemical composition (\% of DM) & 0.5 & \\
$\mathrm{ME}^{4}$ (Mcal/kg) & & 2.85 \\
$\mathrm{NE}_{\mathrm{G}}{ }^{4}$ (Mcal/kg) & 2.82 & 1.25 \\
$\mathrm{DM}$ & 1.25 & 92 \\
$\mathrm{CP}$ & 90 & 19.73 \\
$\mathrm{NDF}$ & 19.61 & 24.5 \\
Ether extract & 23.0 & 3.87 \\
Ash & 3.96 & 11.4 \\
$\mathrm{Ca}^{4}$ & 11.2 & 0.78 \\
$\mathrm{P}^{4}$ & 0.75 & 0.47 \\
\hline
\end{tabular}

${ }^{1}$ Control $=$ diet without alfalfa hay; $12.5 \% \mathrm{AH}=\operatorname{diet}$ with $12.5 \%$ alfalfa hay; $25 \% \mathrm{AH}=$ diet with $25 \%$ alfalfa hay.

${ }^{2}$ Prilled saturated FFA (Milk Specialties, Dundee, IL).

${ }^{3}$ Contained per kilogram of supplement: 250,000 IU of vitamin A, $50,000 \mathrm{IU}$ of vitamin D, 1,500 IU of vitamin E, $2.25 \mathrm{~g}$ of Mn, $120 \mathrm{~g}$ of $\mathrm{Ca}, 7.7 \mathrm{~g}$ of $\mathrm{Zn}, 20 \mathrm{~g}$ of P, $20.5 \mathrm{~g}$ of $\mathrm{Mg}, 186 \mathrm{~g}$ of Na, $1.25 \mathrm{~g}$ of Fe, $3 \mathrm{~g}$ of S, $14 \mathrm{mg}$ of Co, $1.25 \mathrm{~g}$ of $\mathrm{Cu}, 56 \mathrm{mg}$ of I, and $10 \mathrm{mg}$ of Se.

${ }^{4}$ Calculated from NRC (2001).

Behavioral data were monitored by direct observations of all calves as the total time (min) devoted to each monitored behavior for a duration of $4 \mathrm{~d}$, at $2 \mathrm{wk}$ before weaning (d 37 and 44 of the experiment) and 2 wk after weaning (d 58 and 56 of the experiment). Calves were observed $1 \mathrm{~h}$ after the solid feed was offered and $2 \mathrm{~h}$ immediately after the morning milk feeding during the preweaning week. During the postweaning week, calves were observed for $1 \mathrm{~h}$ before and $2 \mathrm{~h}$ after the solid feed was offered. Thus, the total time for observing the behavior of each calf was equal to $12 \mathrm{~h}(6 \mathrm{~h}$ before and $6 \mathrm{~h}$ after weaning). Calves were observed every minute, and the following behaviors were recorded: standing, lying, eating, ruminating, and non-nutritive oral behaviors (when the animal licked any surface, tongue rolled, or consumed wood shavings).

Feces were scored daily for physical shape and consistency according to the procedure described in Heinrichs et al. (2003): $1=$ normal; $2=$ soft to loose; $3=$ loose to watery; $4=$ watery, mucous, slightly bloody; and 5 $=$ watery, mucous, and bloody.

On d 35 and 71 of the study period, rumen fluid samples were obtained by using a stomach tube $4 \mathrm{~h}$ after the morning feeding, and rumen $\mathrm{pH}$ was measured immediately (HI 8318, Hanna Instruments, Cluj-Napoca,
Table 2. Distribution of alfalfa hay with fine and medium particle sizes (PS; mean $\pm \mathrm{SD}$ ) measured as DM retained on sieve (\%)

\begin{tabular}{lcc}
\hline & \multicolumn{2}{c}{ Alfalfa hay } \\
\cline { 2 - 3 } Item & Fine PS & Medium PS \\
\hline $19.0 \mathrm{~mm}$ & 0 & $1.0 \pm 0.2$ \\
$8.0 \mathrm{~mm}$ & $6.5 \pm 0.6$ & $26.0 \pm 1.9$ \\
$1.18 \mathrm{~mm}$ & $50.5 \pm 1.2$ & $35.1 \pm 0.9$ \\
$<1.18 \mathrm{~mm}$ & $42.9 \pm 2.1$ & $37.8 \pm 2.3$ \\
GMPL $^{1}(\mathrm{~mm})$ & $2.1 \pm 0.1$ & $2.9 \pm 0.1$
\end{tabular}

${ }^{1}$ GMPL $=$ geometric mean particle size calculated as described by ASAE (1996; method S424.1).

Romania). Rumen contents were squeezed through 4 layers of cheesecloth and the fluid was stored at $-20^{\circ} \mathrm{C}$ pending analysis. For stabilization, $10 \mathrm{~mL}$ of the rumen fluid was acidified with $3 \mathrm{~mL}$ of $25 \%$ metaphosphoric acid and stored $\left(-20^{\circ} \mathrm{C}\right)$ until analysis for VFA by gas chromatography.

Blood samples were collected $3 \mathrm{~h}$ after the morning meal on d 21, 35, and 74 of the study period. Blood was withdrawn from the jugular vein into evacuated tubes containing $\mathrm{K}_{2}$ EDTA (Becton Dickinson Vacutainer Systems, Franklin Lakes, NJ) and immediately placed on ice. The tubes were then centrifuged at 2,000 $\times g$ $\left(4^{\circ} \mathrm{C}\right)$ for 20 min within $2 \mathrm{~h}$ of sampling. The plasma was separated and stored at $-20^{\circ} \mathrm{C}$ for subsequent analysis.

\section{Chemical and Biochemical Analyses}

Total mixed rations were sampled weekly at the time of feeding and frozen in plastic bags. Samples were thawed and composited into 1 sample per month. The composited samples were mixed thoroughly and ground to pass a 1-mm screen in a Wiley mill (Ogaw Seiki Co. Ltd., Tokyo, Japan) before chemical analyses. Feed and refusal samples were analyzed for their DM content according to the procedures of AOAC (1990). Crude protein (method 988.05; AOAC, 1990) and NDF without the use of sodium sulfite and with $\alpha$-amylase included (Van Soest et al. 1991) were also analyzed.

Rumen samples were analyzed for VFA by gas chromatography (model CP-9002, Chrompack, Middelburg, the Netherlands) with a $50-\mathrm{m}(0.32 \mathrm{~mm}$ i.d. $)$ silicafused column (CP-Wax Chrompack Capillary Column, Varian, Palo Alto, CA). Helium was used as the carrier gas and the oven initial and final temperatures were 55 and $195^{\circ} \mathrm{C}$, respectively. The detector and injector temperatures were set at $250^{\circ} \mathrm{C}$. Crotonic acid (1:7, vol/ vol) was used as the internal standard. Plasma BHBA was determined by autoanalyzer using a laboratory kit (Randox Laboratories Ltd, Ardmore, UK). Plasma concentration of glucose was measured using a serum 
spectrophotometer (UNICCO, 2100, Zistchemi Co., Tehran, Iran).

\section{Statistical Analyses}

Data of DMI, ADG, and gain-to-feed ratio were subjected to ANOVA for a complete randomized design with repeated measurements using PROC MIXED in SAS (version 9.2; SAS Institute, Cary, NC) with the individual calf as the experimental unit. The model included level, PS of AH, the interaction between level and PS of $\mathrm{AH}$, and the interactions of level $\times$ week, PS $\times$ week, and level $\times$ PS $\times$ week for DMI, ADG, and gain-to-feed ratio data. An autoregressive (order 1) covariance structure was chosen based on the Akaike and Bayesian information criteria. Statistical analyses were conducted over 3 periods: preweaning (wk 1 to 7), postweaning (wk 8 to 10), and overall (wk 1 to 10) periods. Rumen fermentation, behaviors, fecal score, and structural growth variables were analyzed using a similar model but without the effect of time. For structural growth variables, the initial measurements were included as a covariate for the statistical analysis of body measurements. When differences for dietary treatments or interactions were detected, means separation was conducted using a Tukey's adjustment for the probability. Significance was declared at $P \leq 0.05$ and trends were considered when $0.05<P<0.10$.

\section{RESULTS}

All the calves were healthy with no clinical symptoms of systemic disease or mortality throughout the experiment.

\section{Calf Performance}

Medium PS promoted total DMI (TDMI) when AH was supplemented at $25 \%$ of dietary DM compared with the $12.5 \%$ level (Figure 1; Table 3). Total DMI was not affected by AH PS during the preweaning period, although TDMI was greater for calves fed MPS than for those fed FPS during the postweaning and overall periods $(P<0.05$; Table 3$)$. Final BW (d 70) increased $(P<0.01)$ from 75.18 to $84.1 \mathrm{~kg}$ when PS changed from fine $(1 \mathrm{~mm})$ to medium $(3 \mathrm{~mm}$; Figure 2; Table 3). Mean ADG and gain-to-feed ratio of the calves did not differ across the treatments before weaning. Regardless of the AH level, ADG was greater in calves fed MPS than in those fed FPS during the postweaning and overall periods $(P<0.01$; Figure 3$)$. No interaction was found in this study between $\mathrm{AH}$ level and PS regarding their effects on TDMI, BW, or ADG. In general, gain-to-feed ratio and fecal score were not affected by AH level, PS, or their interaction $(P>0.05$; Table 3$)$. No significant 2-way interactions (week $\times$ level and week $\times$ PS of $\mathrm{AH}$ ) were found for gain-to-feed ratio, indicating that the effect of level and PS of AH on gain-to-feed ratio was similar throughout the experiment. No significant 3-way interactions (week $\times$ level $\times$ PS of $\mathrm{AH}$ ) were found for $\mathrm{DMI}, \mathrm{ADG}$, and gain-to-feed ratio (Table 3 ).

\section{Rumen Fermentation Parameters and Blood Metabolites}

Regardless of the level of $\mathrm{AH}$, ruminal $\mathrm{pH}$ was greater for MPS than for FPS on d 35 and 70 of the study ( $P$ $<0.01$; Table 4). No interaction was observed between forage PS and the level of AH on ruminal pH (Table 4).

Ruminal $\mathrm{pH}$ was not affected by AH level, PS, or their interaction (Table 4). Regardless of the AH level, acetate concentrations were greater on $\mathrm{d} 70$ of the study in calves fed MPS than in those fed FPS $(P<$ 0.05; Table 4). Regardless of PS, propionate concentration tended to be greater at $12.5 \%$ inclusion of $\mathrm{AH}$ than at 25\% ( $P=0.08$; Table 4$)$. The concentration of butyrate was not affected by AH level, PS, or their interaction. Furthermore, regardless of the AH level, the acetate-to-propionate ratio was greater $(P<0.05)$ on d 35 and 70 of the study in calves fed MPS than in those fed FPS (Table 4). Blood glucose concentration was not affected by AH level, PS, or their interaction (Figure 4). However, regardless of the $\mathrm{AH}$ level, blood BHBA concentrations were greater on $\mathrm{d} 70$ of the study period in calves fed MPS than in those fed FPS $(P<$ 0.05; Figure 5).

\section{Animal Behavior and Structural Growth}

Regardless of AH level, calves receiving the MPS treatment devoted greater time to eating starter feed and ruminating than those receiving FPS $(P<0.01$; Table 5). Moreover, calves on the MPS diet spent less time performing non-nutritive oral behaviors compared with those on the FPS diet (Table 5).

Body length, withers height, heart girth, hip width, and hip height were not affected by AH level, PS, or their interaction (Table 6). However, body girth at the end of experiment increased with increasing PS from fine to medium, regardless of the $\mathrm{AH}$ level $(P<0.05$; Table 6).

\section{DISCUSSION}

\section{Calf Performance}

It has been widely recognized that feeding forage increases postweaning TDMI (Castells et al., 2012; Terré 


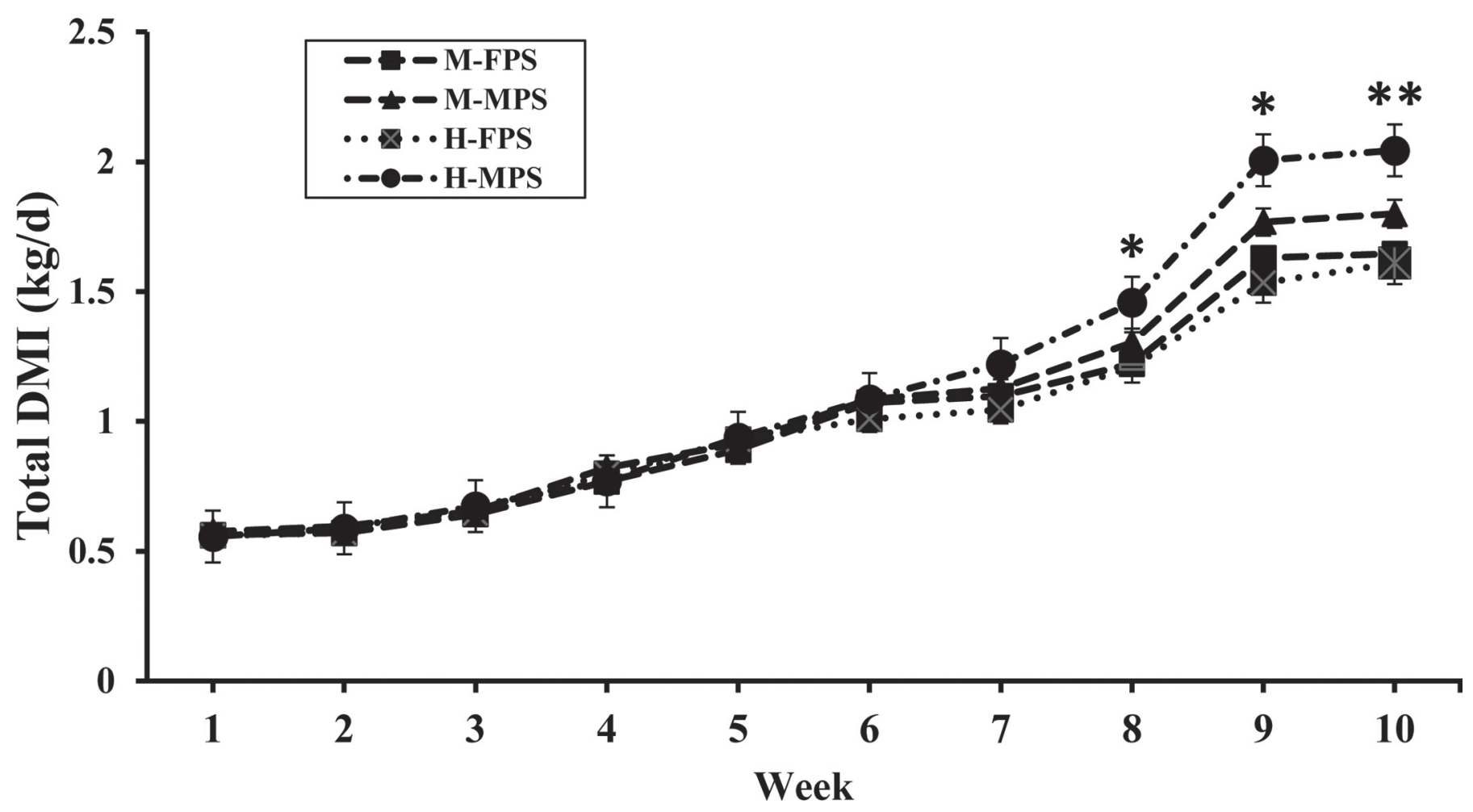

Figure 1. Weekly mean $( \pm \mathrm{SEM})$ total DMI $(\mathrm{kg})$ in calves fed different diets. M-FPS = medium level $(12.5 \%)$ of alfalfa hay $(\mathrm{AH})$ with fine

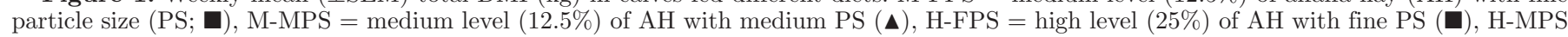
$=$ high level $(25 \%)$ of AH with medium PS $(\bullet)$. For each time point, ${ }^{*}$ denotes significant difference at $P<0.05$; $* *$ denotes significant difference at $P<0.01$.

et al., 2013). It seems that forage particle size may affect postweaning DMI in young calves. Providing AH with a fine PS at medium and high supplementation levels may not have provided sufficient mechanical stimuli to increase the physical capacity and muscular development of the reticulorumen (Tamate et al., 1962), or rumen motility (Nocek, 1997; Owens et al., 1998), resulting in similar values of DMI, BW, ADG, and gainto-feed ratio compared with non-forage-supplemented calves. In the present study, the greater DMI with MPS diets may be explained by the increased capacity and development of the reticulorumen (Khan et al., 2011; Montoro et al., 2013). This is in line with the results of a recent study (Montoro et al., 2013), which showed that the greater PS of grass hay with a DM inclusion level of $10 \%$ improved starter feed intake by dairy calves after weaning. The improved rumen environment and enhanced muscular development of the rumen may, in turn, have contributed to the increased intake of solid feed during the postweaning period (Coverdale et al., 2004; Khan et al., 2011; Castells et al., 2012). Montoro et al. (2013) reported that calves fed 10\% coarsely chopped (3 to $4 \mathrm{~cm}$ ) grass hay tended to have a greater gain-to-feed ratio than those fed $0 \%$ finely ground $(2$ $\mathrm{mm})$ grass hay (0.68 vs. $0.63 \pm 0.02 \mathrm{~kg}$ of gain $/ \mathrm{kg}$ of DMI).

The results obtained for fecal scores are in agreement with those reported by Coverdale et al. (2004) who did not find differences in the fecal scores of calves fed different inclusion levels of bromegrass hay compared with their control group.

\section{Rumen Fermentation Parameters and Blood Metabolites}

In the current study, ruminal $\mathrm{pH}$ ranged from 5.05 to 5.72 in calves supplemented with higher levels of forage after weaning (5.22 to 5.72) compared with before weaning (5.05 to 5.51), which is consistent with the findings of Mirzaei et al. (2015). Anderson et al. (1987) also reported that $\mathrm{pH}$ in the rumen of dairy calves did not exceed 6 during the first 10 wk of life. Krause et al. (2002) reported that mean ruminal pH was positively correlated with the time spent on ruminating and chewing. Our results concerning forage PS are in agreement with those of other authors (Krause et al., 2002; Teimouri Yansari et al., 2004), confirming that forage PS plays a major role in maintaining opti- 
Table 3. Effects of forage level (12.5 vs. 25\%) and particle size (fine vs. medium) on BW, DMI, ADG, gain-to-feed ratio, and fecal score in dairy calves $(\mathrm{n}=15$ per treatment)

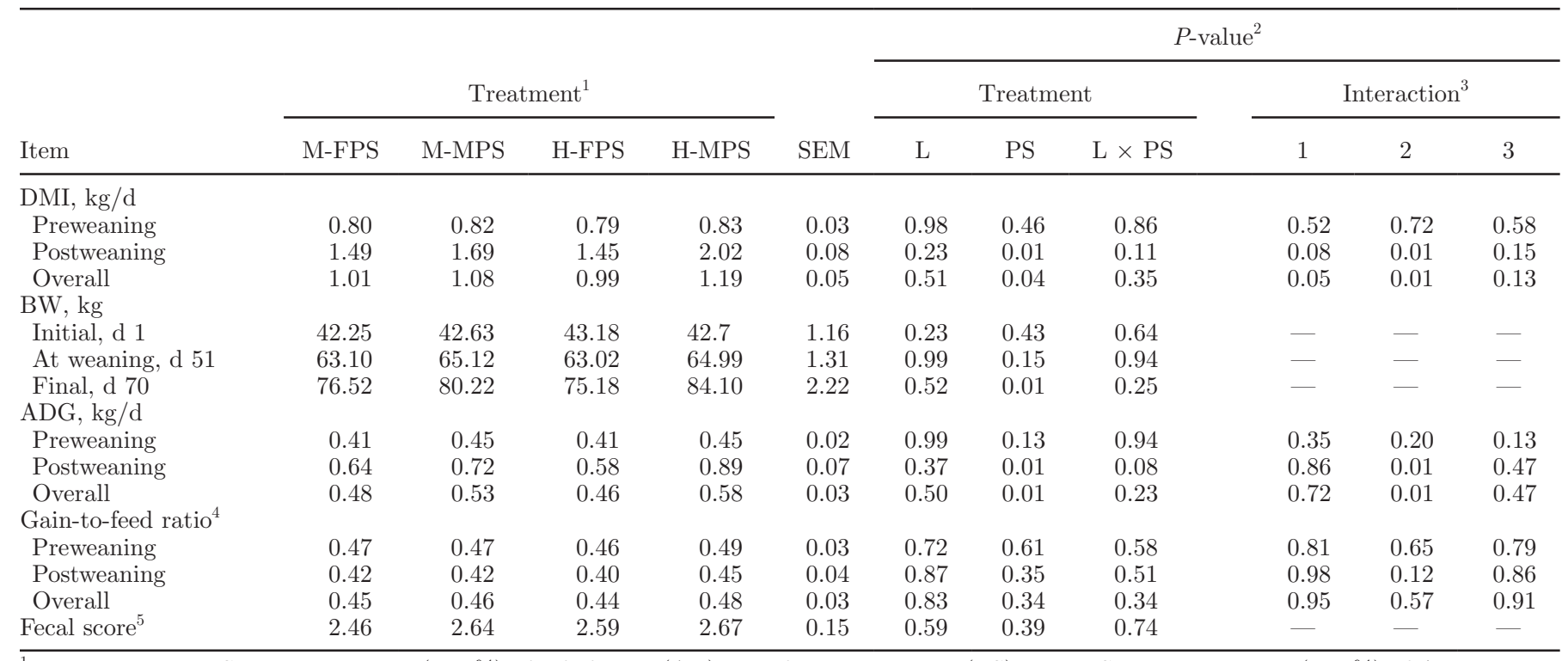

${ }^{1}$ Treatment: M-FPS = medium level $(12.5 \%)$ of alfalfa hay (AH) with fine particle size (PS); M-MPS = medium level (12.5\%) of AH with medium PS; H-FPS = high level (25\%) of AH with fine PS; H-MPS = high level $(25 \%)$ of AH with medium PS.

${ }^{2}$ Statistical comparisons: $\mathrm{L}=$ level of alfalfa hay; PS = particle size of alfalfa hay; $\mathrm{L} \times \mathrm{PS}=\mathrm{L}$ by PS interaction.

${ }^{3}$ Interactions 1,2 , and 3 = level of $\mathrm{AH} \times$ week; PS of $\mathrm{AH} \times$ week; level of $\mathrm{AH} \times \mathrm{PS}$ of $\mathrm{AH} \times$ week.

${ }^{4}$ Gain-to-feed ratio was calculated by dividing ADG (g) by average daily DMI.

${ }^{5}$ Scoring was as follows: $1=$ normal; $2=$ soft to loose; $3=$ loose to watery; 4 = watery, mucous, slightly bloody; $5=$ watery, mucous, and bloody.

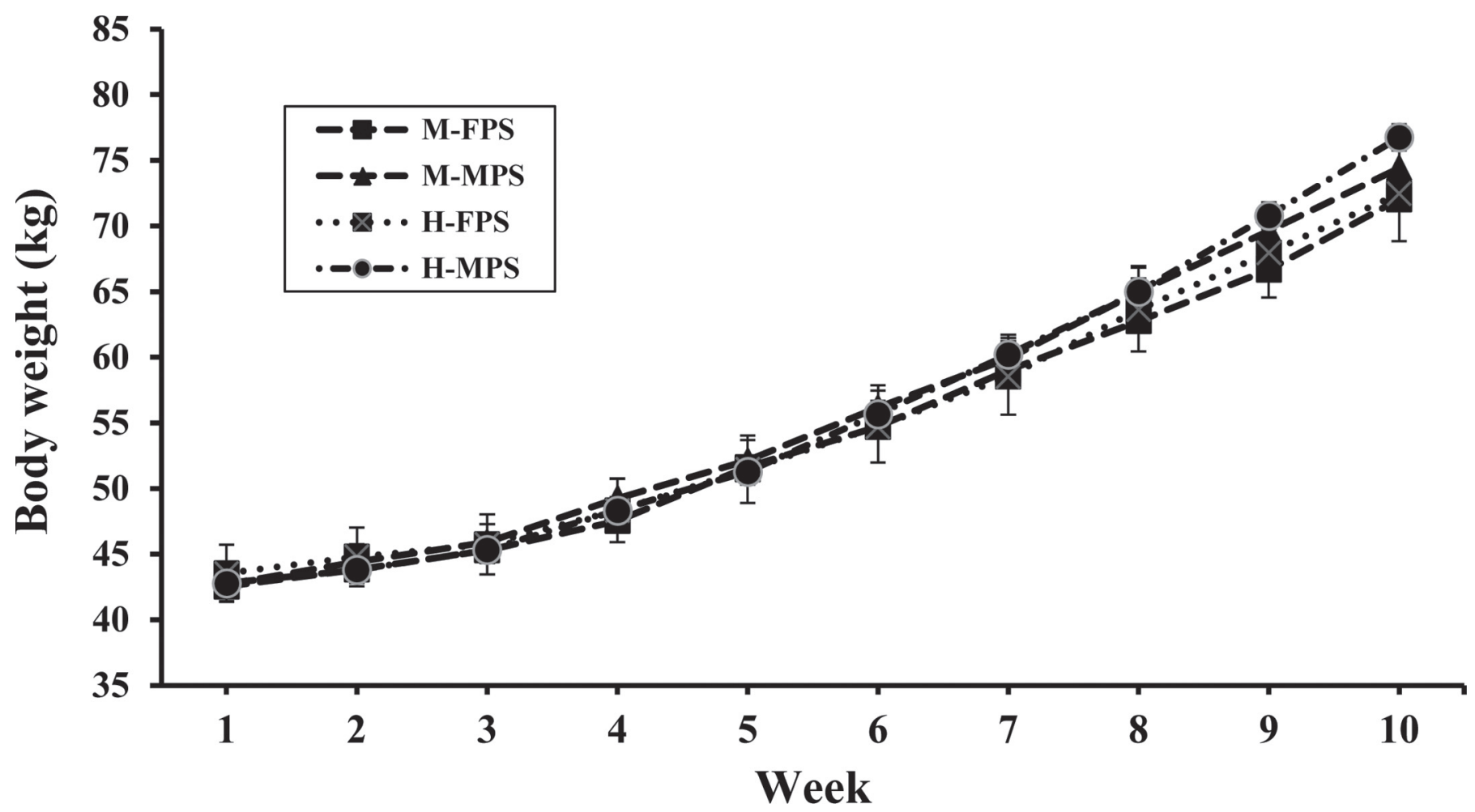

Figure 2. Weekly BW $( \pm$ SEM; $\mathrm{kg})$ in calves fed different diets. M-FPS = medium level $(12.5 \%)$ of alfalfa hay $(\mathrm{AH})$ with fine particle size (PS; $),$ M-MPS = medium level $(12.5 \%)$ of AH with medium PS (ム), H-FPS = high level (25\%) of AH with fine PS (ם), H-MPS = high level $(25 \%)$ of AH with medium PS $(\bullet)$. 
Table 4. Effects of forage level (12.5 vs. $25 \%)$ and particle size (fine vs. medium) on rumen fermentation parameters in dairy calves $(\mathrm{n}=15$ per treatment)

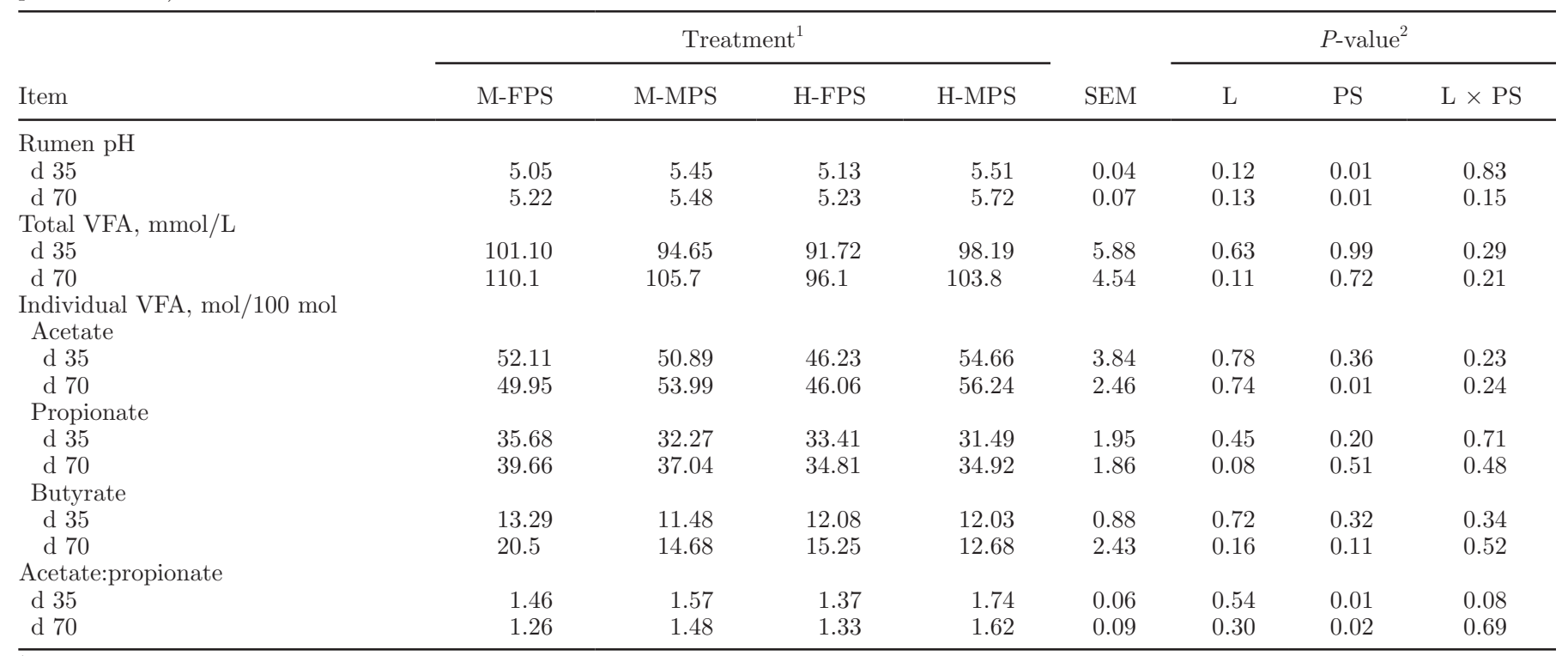

${ }^{1}$ Treatment: M-FPS = medium level (12.5\%) of alfalfa hay (AH) with fine particle size (PS); M-MPS = medium level (12.5\%) of AH with medium PS; H-FPS = high level (25\%) of AH with fine PS; H-MPS = high level (25\%) of AH with medium PS.

${ }^{2}$ Statistical comparisons: $\mathrm{L}=$ level of alfalfa hay; PS = particle size of alfalfa hay; $\mathrm{L} \times \mathrm{PS}=\mathrm{L}$ by PS interaction.

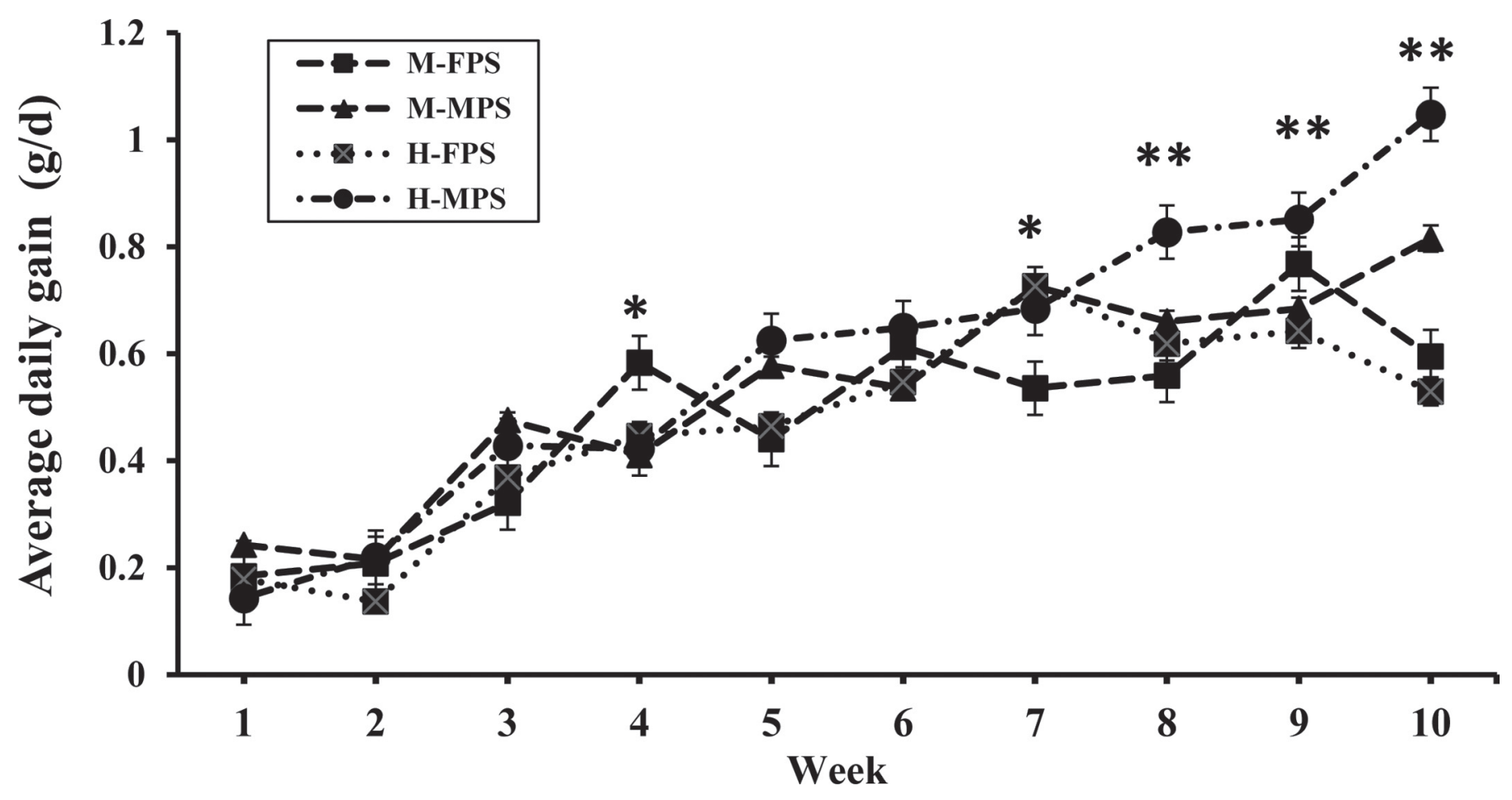

Figure 3. Weekly ADG $( \pm \mathrm{SEM}$; kg) in calves fed different diets. M-FPS = medium level $(12.5 \%)$ of alfalfa hay $(\mathrm{AH})$ with fine particle size (PS; $\boldsymbol{\square})$, M-MPS = medium level $(12.5 \%)$ of AH with medium PS $(\boldsymbol{\Delta})$, H-FPS $=$ high level $(25 \%)$ of AH with fine PS $(\boldsymbol{\square})$, H-MPS $=$ high level $(25 \%)$ of AH with medium PS $(\bullet)$. For each time point, ${ }^{*}=$ significant difference at $P<0.05 ;{ }^{* *}=$ significant difference at $P<0.01$. 


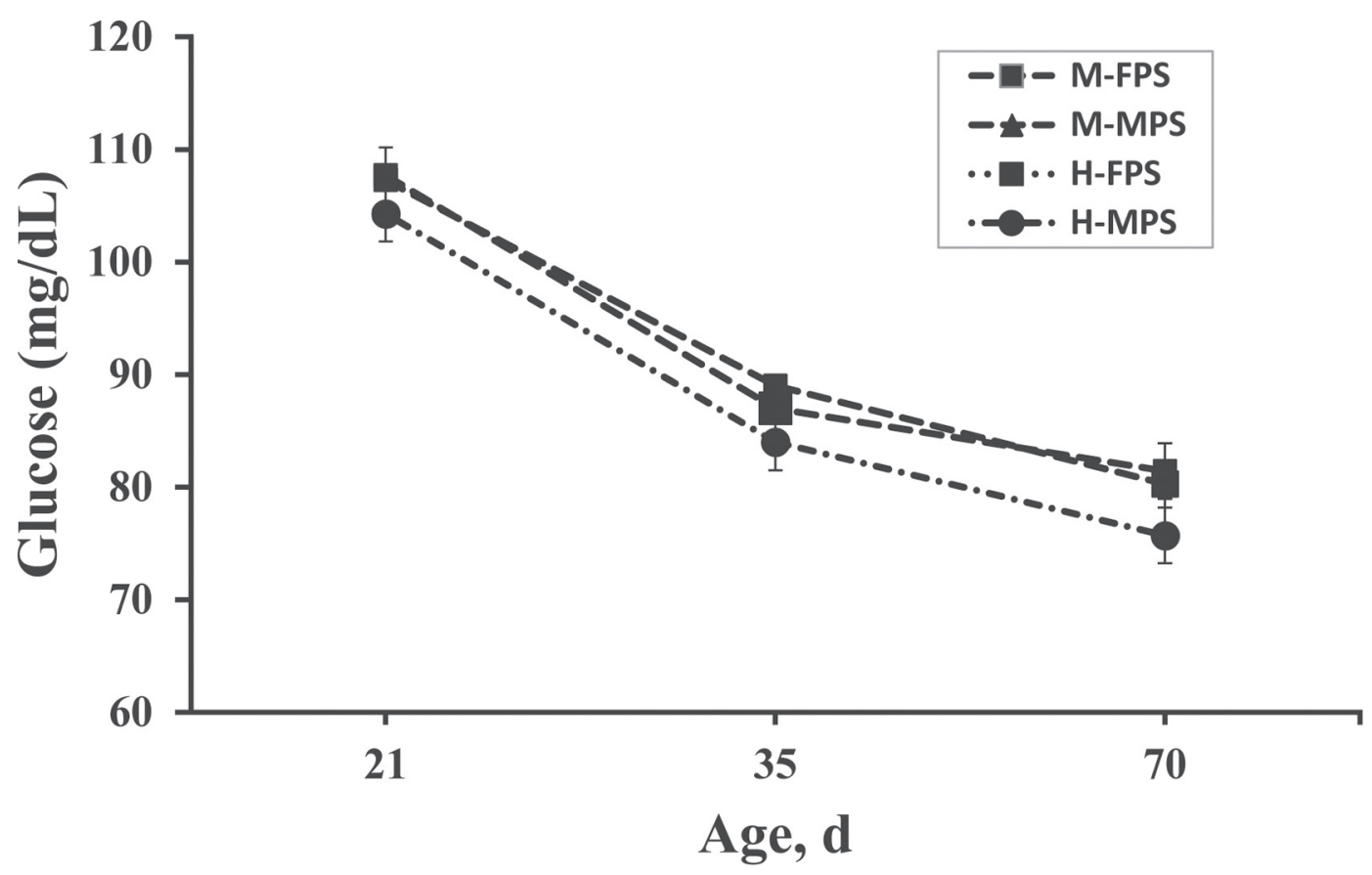

Figure 4. Blood glucose concentrations $( \pm$ SEM; $\mathrm{mg} / \mathrm{dL})$ in calves fed different diets. M-FPS $=$ medium level $(12.5 \%)$ of alfalfa hay $(\mathrm{AH})$

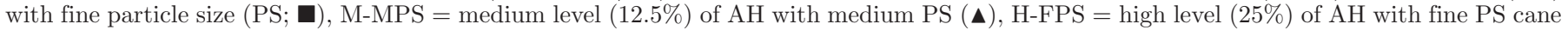
$(\boldsymbol{\square}), \mathrm{H}-\mathrm{MPS}=$ high level $(25 \%)$ of AH with medium PS $(\bullet)$.

mal rumen $\mathrm{pH}$ and that increasing the $\mathrm{PS}$ of $\mathrm{AH}$ can improve ruminal $\mathrm{pH}$, which may be the result of greater time spent ruminating in dairy calves. Nasrollahi et al. (2012) reported that cows fed long AH had higher ruminal $\mathrm{pH}$ compared with those fed finely chopped AH diets (6.46 vs. 6.26). However, this observation is

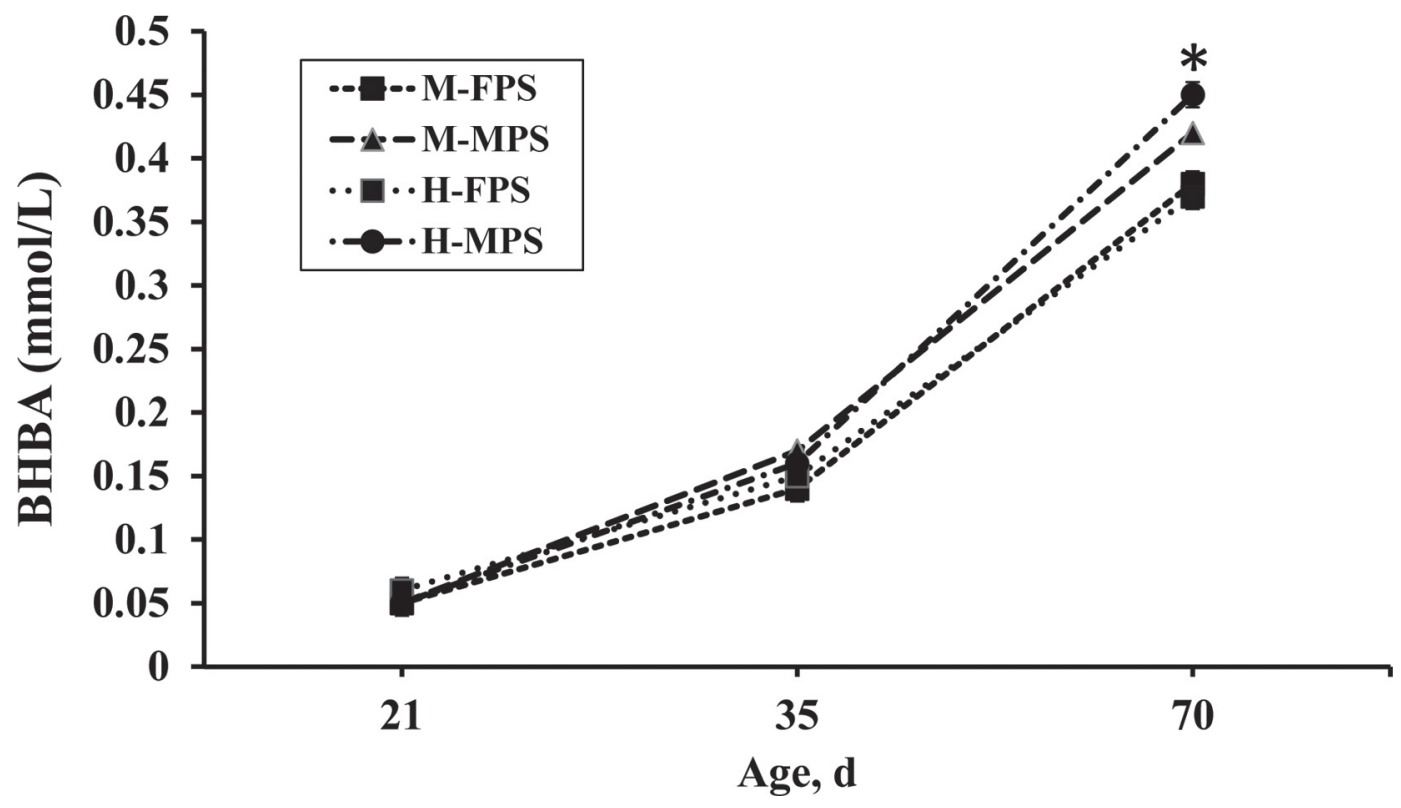

Figure 5. Blood BHBA concentrations $( \pm \mathrm{SEM} ; \mathrm{mmol} / \mathrm{L})$ in calves fed different diets. M-FPS $=$ medium level $(12.5 \%)$ of alfalfa hay $(\mathrm{AH})$ with fine particle size (PS; $\mathbf{\square})$, M-MPS = medium level (12.5\%) of AH with medium PS (ム), H-FPS = high level (25\%) of AH with fine PS (ם), H-MPS $=$ high level $(25 \%)$ of AH with medium PS $(\bullet)$. For each time point, ${ }^{*}=$ significant difference at $P<0.05$. 
Table 5. Effects of forage level (12.5 vs. $25 \%$ ) and particle size (fine vs. medium) on total time devoted to performing different behaviors during $8 \mathrm{~h}$ of observation in dairy calves $(\mathrm{n}=15$ per treatment)

\begin{tabular}{|c|c|c|c|c|c|c|c|c|}
\hline \multirow[b]{2}{*}{ Item } & \multicolumn{4}{|c|}{ Treatment $^{1}$} & \multirow[b]{2}{*}{ SEM } & \multicolumn{3}{|c|}{$P$-value ${ }^{2}$} \\
\hline & M-FPS & M-MPS & H-FPS & H-MPS & & $\mathrm{L}$ & PS & $\mathrm{L} \times \mathrm{PS}$ \\
\hline Lying (min) & 217.5 & 213.9 & 225.3 & 212.6 & 6.59 & 0.58 & 0.25 & 0.45 \\
\hline Eating (min) & 24.15 & 30.93 & 21.13 & 35.52 & 1.43 & 0.72 & 0.01 & 0.06 \\
\hline Ruminating (min) & 21.17 & 33.91 & 20.37 & 39.38 & 2.1 & 0.24 & 0.01 & 0.11 \\
\hline Non-nutritive oral behaviors (min) & 30.42 & 23.20 & 32.95 & 22.98 & 2.5 & 0.65 & 0.01 & 0.59 \\
\hline
\end{tabular}

${ }^{1}$ Treatment: M-FPS = medium level (12.5\%) of alfalfa hay (AH) with fine particle size (PS); M-MPS = medium level (12.5\%) of AH with medium PS; H-FPS = high level $(25 \%)$ of AH with fine PS; H-MPS = high level $(25 \%)$ of AH with medium PS.

${ }^{2}$ Statistical comparisons: $\mathrm{L}=$ level of alfalfa hay; PS = particle size of alfalfa hay; $\mathrm{L} \times \mathrm{PS}=\mathrm{L}$ by PS interaction.

inconsistent with the report of Mirzaei et al. (2015), who found no significant differences in the ruminal $\mathrm{pH}$ of calves fed $\mathrm{AH}$ of different PS.

The total VFA concentrations in the current study were not affected by AH level, PS, or their interaction, which is in agreement with the results reported by Mirzaei et al. (2015). However, previous studies did not observe any differences in total rumen VFA concentrations between calves offered different forage levels and those not receiving any forage (Thomas and Hinks, 1982; Suárez et al., 2007). In the current study, insufficient particle size resulted in reduced ruminal $\mathrm{pH}$ and acetate-to-propionate ratio. The reduction in rumen $\mathrm{pH}$ impairs the growth of cellulolytic bacteria, resulting in declining acetate-to-propionate ratio (Grant et al., 1990).

Blood glucose concentration was also observed to decrease with calf age, which is consistent with the find- ings of Khan et al. (2011). The reduced blood glucose concentration with age observed in calves regardless of treatment may be attributed to a physiological shift in the primary energy source from glucose to VFA when the rumen in young calves becomes functional (Hammon et al., 2002). In agreement with previous studies (Greenwood et al., 1997; Coverdale et al., 2004; Naeem et al., 2012), increasing blood BHBA concentration as calves aged was mainly due to a shift in the sources of physiological fuel during the transition from liquid to solid diets (Khan et al., 2011).

In the current study, the greater concentrations of blood BHBA (an indicator of metabolic function of the rumen wall) in calves fed MPS compared with FPS suggested that ruminal development was normal and that rumen walls were equally efficient in converting butyrate to BHBA (Khan et al., 2011).

Table 6. Effects of forage level (12.5 vs. $25 \%$ ) and particle size (fine vs. medium) on structural growth in dairy calves (n $=15$ per treatment)

\begin{tabular}{|c|c|c|c|c|c|c|c|c|}
\hline Item & \multicolumn{4}{|c|}{ Treatment $^{1}$} & SEM & \multicolumn{3}{|c|}{$P$-value ${ }^{2}$} \\
\hline \multicolumn{9}{|c|}{ Body length } \\
\hline Final & 57.06 & 57.33 & 57.24 & 58.43 & 0.8 & 0.46 & 0.41 & 0.58 \\
\hline \multicolumn{9}{|l|}{ Body girth } \\
\hline Weaning & 108.8 & 111.0 & 109.8 & 113.8 & 1.78 & 0.41 & 0.08 & 0.47 \\
\hline Weaning & 83.52 & 82.74 & 83.44 & 83.80 & 0.71 & 0.49 & 0.77 & 0.42 \\
\hline Final & 85.39 & 84.96 & 85.41 & 85.46 & 0.44 & 0.81 & 0.85 & 0.47 \\
\hline \multicolumn{9}{|l|}{ Heart girth } \\
\hline Weaning & 94.27 & 95.77 & 94.37 & 95.30 & 0.92 & 0.85 & 0.22 & 0.63 \\
\hline Final & 100.7 & 99.9 & 98.9 & 101.6 & 1.57 & 0.96 & 0.41 & 0.13 \\
\hline \multicolumn{9}{|l|}{ Hip width } \\
\hline Weaning & 19.57 & 20.02 & 19.73 & 20.31 & 0.51 & 0.85 & 0.23 & 0.49 \\
\hline
\end{tabular}

${ }^{1}$ Treatment: M-FPS = medium level $(12.5 \%)$ of alfalfa hay $(\mathrm{AH})$ with fine particle size (PS); M-MPS $=$ medium level $(12.5 \%)$ of AH with medium PS; H-FPS = high level $(25 \%)$ of AH with fine PS; H-MPS = high level (25\%) of AH with medium PS.

${ }^{2}$ Statistical comparisons: $\mathrm{L}=$ level of alfalfa hay; PS $=$ particle size of alfalfa hay; $\mathrm{L} \times \mathrm{PS}=\mathrm{L}$ by PS interaction. 


\section{Animal Behavior and Structural Growth}

The benefits of forage supplementation on stimulating rumination have been previously demonstrated (Phillips, 2004; Martin et al., 2006; Castells et al., 2012). In the current study, the greater DMI of MPS diets compared with FPS diets may have been due to the improved rumen function and the more stable $\mathrm{pH}$ achieved by the increased time spent on rumination and eating starter feed. These findings are in agreement with those reported by Nasrollahi et al. (2012), who also observed an increase in eating time with increasing AH PS in dairy cows. Calves fed the FPS diets, regardless of $\mathrm{AH}$ level, spent greater time performing non-nutritive oral behaviors than those fed the MPS diets. Non-nutritive oral behaviors are often considered an index of poor welfare because they are thought to be related to frustrated feeding activity (Redbo, 1990; Redbo and Nordblad, 1997). The present results suggest that forage PS plays an important role in reducing non-nutritive oral behaviors in young calves; therefore, providing calves with fine forage particles may have some adverse effects on welfare.

The role of forage feeding on the physical development of the rumen has been shown previously (Khan et al., 2011; Mirzaei et al., 2015). In the current study, providing forage, regardless of the level of $\mathrm{AH}$, resulted in enhanced body girth, suggesting that anatomical development and digestive organ growth may be influenced by forage supplementation and the PS of $\mathrm{AH}$ in dairy calves. In contrast to our findings, Mirzaei et al. (2015) reported that the effect of AH PS on rumen development and growth characteristics of dairy calves depended on the level of supplementation.

\section{CONCLUSIONS}

The physical form of $\mathrm{AH}$, in particular its particle size, plays a more important role than its chemical characteristics on performance, feeding behavior, and blood metabolites of dairy calves, especially during the postweaning period. It is possible to develop ruminant diets by altering the PS of $\mathrm{AH}$ from fine to medium to achieve high performance and reduced non-nutritive oral behaviors.

\section{ACKNOWLEDGMENTS}

This study was financed by Isfahan University of Technology (Isfahan, Iran). The authors appreciate the employees of the Ghiam Esfahan Plantation and Domesticated Co. (Isfahan, Iran) for their assistance in animal care. We also thank Paul T. D. Peake (Western Australia, Australia) and Mojtaba Yari (Department of
Animal Science, College of Agriculture, Malayer University, Malayer, Iran) for their insightful comments on this paper.

\section{REFERENCES}

Anderson, K. L., T. G. Nagaraja, J. L. Morrill, T. B. Avery, S. J. Galitzer, and J. E. Boyer. 1987. Ruminal microbial development in conventionally or early-weaned calves. J. Anim. Sci. 64:12151226.

AOAC. 1990. Official Methods of Analysis. 12th ed. Association of Official Analytical Chemists, Washington, DC.

ASAE. 1996. S424.1. Method of determining and expressing particle size of chopped forage materials by sieving. Am. Soc. Agric. Eng., St. Joseph, MI.

Baldwin, R. L. VI, K. R. McLeod, J. L. Klotz, and R. N. Heitmann., 2004. Rumen development, intestinal growth and hepatic metabolism in the pre- and post-weaning ruminant. J. Dairy Sci. 87(E Suppl.):E55-E65.

Beharka, A. A., T. G. Nagaraja, J. L. Morrill, G. A. Kennedy, and R. D. Klemm. 1998. Effects of form of the diet on anatomical, microbial and fermentative development of the rumen of neonatal calves. J. Dairy Sci. 81:1946-1955.

Beiranvand, H., G. R. Ghorbani, M. Khorvash, and M. Kazemi-Bonchenari. 2014a. Forage and sugar in dairy calves' starter diet and their interaction on performance, weaning age and rumen fermentation. J. Anim. Physiol. Anim. Nutr. (Berl.) 98:439-445.

Beiranvand, H., G. R. Ghorbani, M. Khorvash, A. Nabipour, M. Dehghan-Banadaky, A. Homayouni, and S. Kargar. 2014b. Interactions of alfalfa hay and sodium propionate on dairy calf performance and rumen development. J. Dairy Sci. 97:2270-2280.

Castells, L., A. Bach, G. Araujo, C. Montoro, and M. Terré. 2012. Effect of different forage sources on performance and feeding behavior of Holstein calves. J. Dairy Sci. 95:286-293.

Castells, L., A. Bach, A. Aris, and M. Terré. 2013. Effects of forage provision to young calves on rumen fermentation and development of the gastrointestinal tract. J. Dairy Sci. 96:5226-5236.

Coverdale, J. A., H. D. Tyler, J. D. Quigley III, and J. A. Brumm. 2004. Effect of various levels of forage and form of diet on rumen development and growth in calves. J. Dairy Sci. 87:2554-2562.

Drackley, J. K. 2008. Calf nutrition from birth to breeding. Vet. Clin. North Am. Food Anim. Pract. 24:55-86.

Fox, D. G., T. P. Tylutki, K. J. Czymmek, C. N. Rasmussen, and V. M. Durbal. 2000. Development and application of the Cornell university nutrient management planning system. Pages 167-179 in Proc. Cornell Nutrition Conf. Feed Manuf., Rochester, NY. Cornell University, Ithaca, NY.

Godden, S., D. Haines, and D. Hagman. 2009. Improving passive transfer of immunoglobulins in calves I: Dose effect of feeding a commercial colostrum replacer. J. Dairy Sci. 92:1750-1757.

Grant, R. J., V. F. Colenbrander, and D. R. Mertens. 1990. Milk fat depression in dairy cows: Role of silage particle size. J. Dairy Sci. 73:1834-1842.

Greenwood, R. H., J. L. Morril, E. C. Titgemeyer, and G. A. Kennedy. 1997. A new method of measuring diet abrasion and its effect on the development of the forestomach. J. Dairy Sci. 80:2534-2541.

Hammon, H. M., G. Schiessler, A. Nussbaum, and J. W. Blum. 2002. Feed intake patterns, growth performance, and metabolic and endocrine traits in calves fed unlimited amounts of colostrum and milk by automate, starting in the neonatal period. J. Dairy Sci. 85:3352-3362.

Heinrichs, A. J., C. M. Jones, L. R. VanRoekel, and M. A. Fowler. 2003. Calf Track: A system of dairy calf workforce management, training, and evaluation and health evaluation. J. Dairy Sci. 86(Suppl. 1):115. (Abstr.)

Hill, T. M., H. G. Bateman, J. M. Aldrich, and R. L. Schlotterbeck. 2008. Effects of the amount of chopped hay or cottonseed hulls in a textured calf starter on young calf performance. J. Dairy Sci. $91: 2684-2693$. 
Hill, T. M., H. G. Bateman, J. M. Aldrich, and R. L. Schlotterbeck. 2009. Roughage for diets fed to weaned dairy calves. Prof. Anim. Sci. 25:283-288.

Iranian Council of Animal Care. 1995. Guide to the Care and Use of Experimental Animals, Vol. 1. Isfahan University of Technology, Isfahan, Iran.

Laarman, A., and M. Oba. 2011. Short communication: Effect of calf starter on rumen $\mathrm{pH}$ of Holstein dairy calves at weaning. J. Dairy Sci. 94:5661-5664.

Khan, M. A., H. J. Lee, W. S. Lee, H. S. Kim, K. S. Ki, T. Y. Hur, G. H. Suh, S. J. Kang, and Y. J. Choi. 2007. Structural growth, rumen development, and metabolic and immune responses of Holstein male calves fed milk through step-down and conventional methods. J. Dairy Sci. 90:3376-3387.

Khan, M. A., H. J. Lee, W. S. Lee, H. S. Kim, S. B. Kim, S. B. Park, K. S. Baek, J. K. Ha, and Y. J. Choi. 2008. Starch source evaluation in calf starter: II. Ruminal parameters, rumen development, nutrient digestibilities, and nitrogen utilization in Holstein calves. J. Dairy Sci. 91:1140-1149.

Khan, M. A., D. M. Weary, and M. A. G. von Keyserlingk. 2011. Hay intake improves performance and rumen development of calves fed higher quantities of milk. J. Dairy Sci. 94:3547-3553.

Krause, K. M., D. K. Combs, and K. A. Beauchemin. 2002. Effects of forage, particle size, and grain fermentability in midlactation cows. I. Milk production and diet digestibility. J. Dairy Sci. 85:19361946.

Lesmeister, K. E., and A. J. Heinrichs. 2004. Effects of corn processing on growth characteristics, rumen development, and rumen parameters in neonatal dairy calves. J. Dairy Sci. 87:3439-3450.

Martin, C., L. Brossard, and M. Doreau. 2006. Mechanisms of appearance of ruminal acidosis and consequences on physiopathology and performances. Prod. Anim. 19:93-107.

Mirzaei, M., M. Khorvash, G. R. Ghorbani, M. Kazemi-Bonchenari, A. Riasi, A. Nabipour, and J. J. G. C. van den Borne. 2015. Effects of supplementation level and particle size of alfalfa hay on growth characteristics and rumen development in dairy calves. J. Anim. Physiol. Anim. Nutr. (Berl.) 99:553-564.

Montoro, C., E. K. Miller-Cushon, T. J. DeVries, and A. Bach. 2013. Effect of physical form of forage on performance, feeding behavior, and digestibility of Holstein calves. J. Dairy Sci. 96:1117-1124.

Naeem, A., J. K. Drackley, J. Stamey, and J. J. Loor. 2012. Role of metabolic and cellular proliferation genes in ruminal development in response to enhanced plane of nutrition in neonatal Holstein calves. J. Dairy Sci. 95:1807-1820.
Nasrollahi, S. M., M. Khorvash, G. R. Ghorbani, A. Teimouri-Yansari, A. Zali, and Q. Zebeli. 2012. Grain fermentability and marginal changes in forage particle size modulated digestive processes, and nutrient intake in dairy cows. Animal 6:1237-1245.

NRC. 2001. Nutrient Requirements of Dairy Cattle. 7th rev. ed. National Academies Press, Washington, DC.

Nocek, J. E. 1997. Bovine acidosis: Implications on laminitis. J. Dairy Sci. 80:1005-1028.

Owens, F. N., D. S. Secrist, W. J. Hill, and D. R. Gill. 1998. Acidosis in cattle: A review. J. Anim. Sci. 76:275-286.

Phillips, C. J. C. 2004. The effects of forage provision and group size on the behavior of calves. J. Dairy Sci. 87:1380-1388.

Redbo, I. 1990. Changes in duration and frequency of stereotypies and their adjoining behaviours in heifers, before, during and after the grazing period. Appl. Anim. Behav. Sci. 26:57-67.

Redbo, I., and A. Nordblad. 1997. Stereotypies in heifers are affected by feeding regime. Appl. Anim. Behav. Sci. 53:193-202.

Suárez, B. J., C. G. V. Reenen, N. Stockhofe, J. Dijkstra, and W. J. J. Gerrits. 2007. Effect of roughage source and roughage to concentrate ratio on animal performance and rumen development in veal calves. J. Dairy Sci. 90:2390-2403.

Stobo, I. J. F., J. H. B. Roy, and H. J. Gaston. 1966. Rumen development in the calf. 1. The effect of diets containing different proportions of concentrates to hay on rumen development. Br. J. Nutr. 20:171-188.

Tamate, H., A. D. McGilliard, N. L. Jacobson, and R. Getty. 1962. Effect of various dietaries on the anatomical development of the stomach in the calf. J. Dairy Sci. 45:408-420.

Teimouri Yansari, A., R. Valizadeh, A. Naserian, D. A. Christensen, P. $\mathrm{Yu}$, and F. E. Shahroodi. 2004. Effects of alfalfa particle size and specific gravity on chewing activity, digestibility, and performance of Holstein dairy cows. J. Dairy Sci. 87:3912-3924.

Terré, M., E. Pedrals, A. Dalmau, and A. Bach. 2013. What do preweaned and weaned calves need in the diet: A high fiber content or a forage source? J. Dairy Sci. 96:5217-5225.

Thomas, D. B., and C. E. Hinks. 1982. The effect of changing the physical form of roughage on the performance of the early-weaned calf. Anim. Prod. Sci. 35:375-384.

Van Soest, P. J., J. B. Robertson, and B. A. Lewis. 1991. Methods for dietary fiber, neutral detergent fiber nonstarch polysaccharide in relation to animal nutrition. J. Dairy Sci. 74:3583-3597. 